\title{
Editorial on Special Issue "Textile-Reinforced Cement Composites: New Insights into Structural and Material Engineering"
}

\author{
Tine Tysmans *(i) and Jan Wastiels $\mathbb{D}$ \\ Department Mechanics of Materials and Constructions, Vrije Universiteit Brussel (VUB), Pleinlaan 2, \\ 1050 Brussels, Belgium; jan.wastiels@vub.be \\ * Correspondence: Tine.Tysmans@vub.be
}

Received: 20 December 2019; Accepted: 23 December 2019; Published: 13 January 2020

\begin{abstract}
This special issue presents the latest advances in the field of Textile-Reinforced Cement Composites, including Textile-Reinforced Concrete (TRC), Textile-Reinforced Mortar (TRM), Fabric-Reinforced Cementitious Matrix (FRCM), etc. These composite materials distinguish themselves from other fibre reinforced concrete materials by their strain-hardening behaviour under tensile loading. This Special Issue is composed of 14 papers covering new insights in structural and material engineering. The papers include investigations on the level of the fibre reinforcement system as well as on the level of the composites, investigating their impact and fatigue behaviour, durability and fire behaviour. Both strengthening of existing structures and development of new structural systems such as lightweight sandwich systems are presented, and analysis and design methods are discussed. This Special Issue demonstrates the broadness and intensity of the ongoing advancements in the field of Textile-Reinforced Cement composites and the importance of several future research directions.
\end{abstract}

Keywords: cement composites; fibre; textile; textile-reinforced concrete; textile-reinforced mortar

\section{Introduction}

As sustainability is rising higher on the agenda, research towards new construction materials and systems has gained importance. One of the new material systems that has been investigated over the last few decades is textile-reinforced cement composites. These materials are known under different names, e.g., Textile-Reinforced Concrete (TRC) or Cement, Textile-Reinforced Mortar (TRM), and Fabric-Reinforced Cementitious Matrix (FRCM). All of these composite materials are characterized by a cementitious matrix material reinforced by textiles to provide for continuous fibre reinforcement in such a way that they show strain hardening behaviour under tensile loading.

Thanks to this tensile capacity provided by the textiles, traditional steel reinforcement can be omitted and the thickness of the concrete cover that is used to prevent the steel from corroding can be significantly reduced. As a result, thin concrete elements can be designed with a slenderness that cannot be achieved with traditional steel-reinforced concrete. As the dimensions of the concrete elements are reduced, the amount of concrete used, the weight of the elements, the emissions due to transport of the materials, etc., are also reduced. On top of this, the sustainability of the building elements can be increased because the flexible fibre reinforcement allows for the design of structural elements in optimal shapes, with tailored fibre textiles. 


\section{TRC in Structural and Material Engineering}

The motivation for this Special Issue was the potential of TRC composites to contribute to a sustainable built environment. It presents the latest insights and results from the research community dealing with TRC composites on both the material level and the structural level. On the material level, much research has been carried out towards the optimization of the fibre reinforcement system. On the structural level, many researchers have investigated new structural systems that can benefit from the slenderness and low weight of TRCs, and methods to analyze loadbearing behaviour and design these new applications. Finally, the durability of the composites and their behaviour under an elevated temperature (including in fire) are important fields of investigation, both on the material level and the structural level. In total, 21 papers were submitted, and 14 were accepted.

Three papers focus on the reinforcement system. Although carbon or AR (alkali-resistant) glass fibres are used as the reinforcement material for TRCs in all other papers in this Special Issue due to their stiffness and strength properties, the paper by Mobasher, Dey, Bauchmoyer, Mehere, and Schaef [1] analyses the effect of high-toughness hydrophilic PP fibres on the cracking distribution associated with strengthening and toughening. The paper by Rampini, Zani, Colombo, and di Prisco [2] presents extensive experimental results of tensile tests on a wide set of AR glass fabrics and TRCs. The effect of the fabric coating and the addition of short fibres on the load capacity and the energy absorption is discussed. A hybrid fibre system is also used in the contribution by Gong, Heravi, Alsous, Curosu, and Mechtcherine [3], where the synergetic action between a carbon grid and short PE or PBO fibres is investigated in quasi-static uniaxial tensile tests, pull-out tests at different strain rates, and split Hopkinson impact tests.

Long-term durability is discussed and experimentally investigated in the paper by Spelter, Bergmann, Bielak, and Hegger [4], leading to the conclusion that it appears to be possible that no reduction due to external influences is necessary for the investigated type of carbon reinforcement. The effect of fatigue is treated in two contributions. The paper by De Munck, Tysmans, Wastiels, Kapsalis, Vervloet, El Kadi, and Remy [5] presents the effect of 100,000 loading cycles at serviceability load levels on the residual behaviour during uniaxial coupon tensile tests and four-point bending tests on sandwich panels reinforced with AR glass textiles. The paper by Wagner and Curbach [6] examines the bond fatigue of TRC with epoxy-impregnated carbon textiles as a function of the anchorage length and the load level, and presents the obtained results in S-N diagrams. The effect of an elevated temperature $\left(120^{\circ} \mathrm{C}\right.$ and $\left.200{ }^{\circ} \mathrm{C}\right)$ on the shear bond to masonry is treated in the feature paper by Askouni, Papanicolaou, and Kaffetzakis [7], using AR glass textiles with a normal weight and a lightweight mortar. The degradation of TRCs with SBR-coated carbon or AR glass textiles is treated in the paper by Kapsalis, El Kadi, Vervloet, De Munck, Wastiels, Triantafillou, and Tysmans [8].

The design of TRC structures is treated in four contributions. The paper by Flansbjer, Williams, Portal, and Vennetti [9] verifies the structural performance of non-load-bearing sandwich façade elements through a large-scale experimental program focused on anchorage and wind load tests, as well as through numerical modeling as validation. The paper by Vervloet, Tysmans, El Kadi, De Munck, Kapsalis, Van Itterbeeck, Wastiels, and Van Hemelrijck [10] focuses on the large-scale experimental validation of a numerical bending model for sandwich beams with TRC faces reinforced with two-dimensional (2D) and three-dimensional (3D) AR glass textiles. The shear capacity of carbon TRC slabs without shear reinforcement is investigated by Bielak, Adam, Hegger, and Classen [11] through three-point bending tests with a different shear slenderness. The results are compared to existing models and design provisions. The feature review paper by Scheerer, Zobel, Müller, Senckpiel-Peters, Schmidt, and Curbach [12] elaborates on design rules for the flexural strengthening of reinforced concrete structures with TRC, and highlights some practical applications.

The feature paper by Chudoba, Sharei, Senckpiel-Peters, and Schladitz [13] contributes to the discussion on macro-scale modeling methods for the structural analysis of thin-walled concrete shells reinforced with a layup of non-metallic fabrics. Large scale tests are performed on carbon-reinforced 
shell ceiling elements, and a smeared crack cross-section model is proposed, calibrated, and verified with a numerical analysis.

A final paper by Asgharzadeh and Raupach [14] proposes a specific application in which carbon textiles are, besides their use as a structural reinforcement, intended to act as an anode material for cathodic corrosion protection.

\section{Conclusions}

This Special Issue presents great advancements in the field of Textile-Reinforced Cement composites, as well as future research directions. Another essential step that we expect in the future is the translation of these research results into tangible design guidelines for the construction industry.

Author Contributions: Both authors have contributed to the conceptualization, writing, review and editing of this manuscript. Both authors have read and agreed to the published version of the manuscript.

Funding: This research received no external funding.

Acknowledgments: Thanks are due to all of the authors and peer reviewers for their valuable contributions to this Special Issue. The editorial team at MDPI has been of great help; special thanks go to Jennifer Li, Managing Editor for the Acoustics and Vibration Section.

Conflicts of Interest: The authors declare no conflict of interest.

\section{References}

1. Mobasher, B.; Dey, V.; Bauchmoyer, J.; Mehere, H.; Schaef, S. Reinforcing efficiency of micro and macro continuous polypropylene fibers in cementitious composites. Appl. Sci. 2019, 9, 2189. [CrossRef]

2. Rampini, M.C.; Zani, G.; Colombo, M.; di Prisco, M. Mechanical behaviour of TRC composites: Experimental and analytical approaches. Appl. Sci. 2019, 9, 1492. [CrossRef]

3. Gong, T.; Heravi, A.A.; Alsous, G.; Curosu, I.; Mechtcherine, V. Impact-tensile behavior of cementitious composites reinforced with carbon textile and short polymer fibers. Appl. Sci. 2019, 9, 4048. [CrossRef]

4. Spelter, A.; Bergmann, S.; Bielak, J.; Hegger, J. Long-term durability of carbon-reinforced concrete: An overview and experimental investigations. Appl. Sci. 2019, 9, 1651. [CrossRef]

5. De Munck, M.; Tysmans, T.; Wastiels, J.; Kapsalis, P.; Vervloet, J.; El Kadi, M.; Remy, O. Fatigue behaviour of textile reinforced cementitious composites and their application in sandwich elements. Appl. Sci. 2019, 9, 1293. [CrossRef]

6. Wagner, J.; Curbach, M. Bond fatigue of TRC with epoxy impregnated carbon textiles. Appl. Sci. 2019, 9, 1980. [CrossRef]

7. Askouni, P.D.; Papanicolaou, C.G.; Kaffetzakis, M.I. The effect of elevated temperatures on the TRM-to-masonry bond: Comparison of normal weight and lightweight matrices. Appl. Sci. 2019, 9, 2156. [CrossRef]

8. Kapsalis, P.; El Kadi, M.; Vervloet, J.; De Munck, M.; Wastiels, J.; Triantafillou, T.; Tysmans, T. Thermomechanical behavior of textile reinforced cementitious composites subjected to fire. Appl. Sci. 2019, 9, 747. [CrossRef]

9. Flansbjer, M.; Williams Portal, N.; Vennetti, D. Verification of the structural performance of textile reinforced reactive powder concrete sandwich façade elements. Appl. Sci. 2019, 9, 2456. [CrossRef]

10. Vervloet, J.; Tysmans, T.; El Kadi, M.; DE Munck, M.; Kapsalis, P.; Van Itterbeeck, P.; Wastiels, J.; Van Hemelrijck, D. Validation of a numerical bending model for sandwich beams with textile-reinforced cement faces by means of digital image correlation. Appl. Sci. 2019, 9, 1253. [CrossRef]

11. Bielak, J.; Adam, V.; Hegger, J.; Classen, M. Shear capacity of textile-reinforced concrete slabs without shear reinforcement. Appl. Sci. 2019, 9, 1382. [CrossRef]

12. Scheerer, S.; Zovel, R.; Müller, E.; Senckpiel-Peters, T.; Schmidt, A.; Curbach, M. Flexural strengthening of RC structures with TRC—Experimental observations, design approach and application. Appl. Sci. 2019, 9, 1322. [CrossRef] 
13. Chudoba, R.; Sharei, E.; Senckpiel-Peters, T.; Schladitz, F. Numerical modeling of non-uniformly reinforced carbon concrete lightweight ceiling elements. Appl. Sci. 2019, 9, 2348. [CrossRef]

14. Asgharzadeh, A.; Raupach, M. Damage mechanisms of polymer impregnated carbon textiles used as anode material for cathodic protection. Appl. Sci. 2019, 9, 110. [CrossRef]

(C) 2020 by the authors. Licensee MDPI, Basel, Switzerland. This article is an open access article distributed under the terms and conditions of the Creative Commons Attribution (CC BY) license (http://creativecommons.org/licenses/by/4.0/). 